\title{
Balkanologie
}

Balkanologie Revue d'études pluridisciplinaires

Vol. VII, n 2 | 2003

Volume VII Numéro 2

\section{Jean-Claude FAVEYRIAL, Histoire de l'Albanie}

Édition établie et présentée par Robert Elsie, Pejë : Dukagjini, Publishing House, 2001, XVIII + 426 p.

Michel Roux

\section{(2) OpenEdition}

\section{Journals}

Édition électronique

URL : http://journals.openedition.org/balkanologie/1967

DOI : 10.4000/balkanologie. 1967

ISSN : 1965-0582

Éditeur

Association française d'études sur les Balkans (Afebalk)

Édition imprimée

Date de publication : 1 décembre 2003

Pagination : 229-230

ISSN : 1279-7952

\section{Référence électronique}

Michel Roux, "Jean-Claude FAVEYRIAL, Histoire de l'Albanie », Balkanologie [En ligne], Vol. VII, n 2 I

2003, mis en ligne le 19 février 2009, consulté le 17 décembre 2020. URL : http://

journals.openedition.org/balkanologie/1967 ; DOI : https://doi.org/10.4000/balkanologie.1967

(C) Tous droits réservés 


\section{Jean-Claude FAVEYRIAL, \\ Histoire de l'Albanie, édition établie et présentée par Robert Elsie, Pejë : Dukagjini Publishing House, 2001, XVIII + 426 p.}

Ce livre, écrit entre 1884 et 1889 , est sans doute la plus ancienne étude qui retrace l'histoire de l'Albanie, de l'Antiquité à l'époque même de sa rédaction. Son auteur, né à Usson en Forez (Puy-de-Dôme) en 1817, admis dans la Congrégation de la Mission Lazariste à Paris en 1843 après des études secondaires au séminaire de Lyon, ordonné prêtre en 1845 , accomplit toute sa carrière dans l'Empire ottoman, principalement à Istanbul puis à Monastir (Bitola), où il fut professeur de français et de philosophie au lycée valaque et où il mourut en 1893 après avoir vécu près d'un demi-siècle dans la péninsule des Balkans (qu'il nommait presqu'île illyrienne). Il laissa une œuvre considérable, pour l'essentiel non publiée.

Le manuscrit de l'Histoire de l'Albanie, découvert en 1999 à Paris dans les archives de son ordre, vient d'être publié par Dukagjini, un éditeur albanais du Kosovo établi à Pejë, ville plus connue dans le reste du monde sous son nom serbe de Peć. Le balkanologue canadien Robert Elsie, dans la présentation qu'il en fait, souligne qu'il s'agit plus largement d'une histoire du sud-ouest des Balkans qui prend également en compte le Monténégro, la Macédoine et l'Épire. Ceci s'explique aisément : les Albanais vivaient mêlés à d'autres peuples, leur affirmation nationale n'en était qu'à ses débuts et le nom d'Albanie désignait une entité géographique floue, pas encore un État. Mais l'auteur donne de son choix une autre raison : rappelant que l'Albanie et sa périphérie étaient caractérisés, selon Strabon, par une unité de langue et de culture, il estime que cette Illyrie a vocation à réaliser son unité politique - vocation toujours contrariée - et doit être traitée comme un ensemble.

Lire aujourd'hui ce travail antérieur à toute la production historique moderne consacrée à l'Albanie fait évidemment apparaître des décalages entre les méthodes, les problématiques, les sources et niveaux d'information, les idéologies des historiens récents ou actuels et celles de l'auteur. Il est curieux d'y lire que les Ottomans ne sont pas des Turcs, mais des Celtes (les Galates) dont " l'esprit de Mahomet fit des conquérants " (p. 187), ou d'y découvrir une problématique amorcée en ces termes : " comme ici-bas rien ne peut arriver que par l'or- 
dre ou la permission de Dieu, l'historien (...) se demande quelles raisons Dieu peut avoir eu de substituer un État musulman à des États chrétiens " (p. 184). L'hypothèse de l'auteur est alors qu'il s'agit de l'abaissement moral des princes et du clergé des pays en question. Audelà de ces détails, sa lecture me paraît présenter un triple intérêt :

- tout d'abord, il s'agit d'un ouvrage solidement documenté, synthèse de la plupart des sources publiées antérieures, enrichie par des emprunts à la presse et aux textes officiels de son temps ainsi que par des récits de voyageurs et par l'expérience propre de l'auteur. Il fournit en particulier des indications intéressantes sur les "chrétiens occultes" ayant en apparence embrassé l'islam, et sur la compétition pour l'ouverture d'écoles en langue valaque, bulgare, albanaise, contemporaine de sa rédaction. Au total, il apparait représentatif de l'état des connaissances et du primat de l'histoire événementielle dans les textes d'alors ;

- ensuite, ce livre témoigne des points de vue, des passions et des engagements d'un missionnaire catholique, fort hostile aux Grecs et à leur Église qu'il considère à la fois comme impérialistes sur le plan confessionnel, culturel et linguistique et comme favorisant la division et l'animosité entre les peuples des Balkans, donc l'affaiblissement politique de cette région où, estime-il, " le moment de former un grand état est à jamais perdu " (préface, p. XV). Il y a là une vision géopolitique quelque peu prémonitoire. C'est d'ailleurs ce parti-pris qui explique que Faveyrial se soit engagé en faveur du mouvement national bulgare (jusqu'à agacer sa propre hiérarchie, d'où sa mutation d'Istanbul à Monastir), puis en faveur des Valaques et des Albanais. Parlant des conversions au rite grec en Albanie du Sud au XIII ${ }^{\mathrm{e}}$ siècle, il déplore qu' " enfants d'une même famille, les Albanais vont méconnaître leurs ancêtres, méconnaître leurs communs intérêts et suivre des directions sociales aussi funestes pour eux que contraires à l'évangile " (p. 170);

- enfin, du fait même des décalages déjà évoqués, cette lecture nous ramène en amont de diverses élaborations intellectuelles ultérieures, nous incitant ainsi à les reconsidérer. Un seul exemple : en 1878, alors que les Puissances européennes voulaient contraindre l'Empire ottoman à céder du territoire au Monténégro, les Albanais avaient constitué, pour s'y opposer, la ligue de Prizren. Faveyrial, tout en notant que la Porte voyait se retourner contre elle un mouvement qu'elle avait d'abord encouragé, détaille l'échec de la première tentative de reprise en main, puis l'écrasement final de la ligue par les forces ottomanes (1881), mais il n'en analyse pas le contenu sociologique, les prises de position et le rôle politique. Au rebours de ce traitement événementiel, qui ne le présente nullement comme une nouveauté, les historiens albanais du $\mathrm{XX}^{\mathrm{e}}$ siècle ont peu à peu construit l'épisode de la ligue de Prizren comme une manifestation essentielle de l'affirmation nationale de leur peuple. Le colloque international tenu à Prizren en juin 2003 à l'occasion de son $125^{\mathrm{e}}$ anniversaire illustre la continuité de cette construction symbolique, au-delà des changements de régime politique, tandis que certains chercheurs en relativisent la portée.

L'éditeur Dukagjini n'a pas de distributeur en France. On peut commander l'ouvrage chez Kubon \& Sagner (à l'attention de Mr Paul H. Dörr), Hess-Str. 39/41, D-80798 München, tél. ++498954218117, fax ++498954218218. 